\title{
When redundancy hurts letter detection: An attempt to define one condition
}

\author{
NEAL F. JOHNSON and ANTHONY J. BLUM \\ The Ohio State University, Columbus, Ohio
}

\begin{abstract}
The issue examined in this study concerns why some experiments have demonstrated that it takes longer to detect the initial letter of a redundant array such as BBBBB than it does to detect a single letter presented in isolation (i.e., the single-letter advantage; Johnson, 1977, 1981, 1986b), whereas other studies have shown no difference in the latency of letter detection under those two conditions (e.g., Krueger \& Shapiro, 1980). The present study involved five experiments that not only ruled out several alternative explanations, but also demonstrated that if the predisplay fixation field provided a clear point the subjects could use as a basis for prefocusing their attention to a narrow spatial extent that included only the location of the up-coming critical letter, there was no single-letter advantage, but that the advantage did occur if such prefocusing were not possible. Consistent with Johnston and McClelland's (1980) model, the results are interpreted as suggesting that what has been taken as evidence of holistic encoding of small visual patterns (e.g., words) also might be interpreted as reflecting the order in which attention is deployed to the patterns once the encoding process is complete.
\end{abstract}

While redundancy normally helps during the processing of information, there seems to be at least one situation in which that is not the case. In particular, if subjects are asked to detect the presence of a predesignated target letter in an upcoming display, they appear to be somewhat slower if the display consists of more than one letter than if it consists of a single letter, and that occurs even when the display is redundant to the extent that it contains multiple instances of the same letter (e.g., BBBBB) (Eriksen \& Schultz, 1979; Johnson, 1981, 1986b). Furthermore, it has been demonstrated that accuracy of report in a tachistoscopic task can be reduced by the presence of a flanking letter that is identical to the target (Bjork \& Murray, 1977).

Although the demonstration of the single-letter advantage (i.e., the shorter latencies obtained when the displays are single letters as opposed to redundant multiletter displays) has emerged in the context of several different traditions, one line of research has focused on the issue of part-wili e relationships in the processing of small visual patterns (Johnson, 1977, 1981, 1986b). The general model under which this work has been done (i.e., the patternunit model) is based on the assumption that when subjects encode a presented visual pattern into memory, their initial attempts always involve trying to encode it as a unit, and their attempts always would succeed if they had a prelearned code for the item (e.g., a name for a letter) or if they knew a rule system that could be used to generate such a code (e.g., a word).

Regardless of whether or not a code were available for representing the display as a unit, this model would predict

The authors' mailing address is Department of Psychology, The Ohio State University, 404C W. 17th (East Stadium), Columbus, OH 43210-1202. that the context of other letters within a display always would delay the point in time when subjects could make a decision as to whether a predesignated target letter matched a letter from the display. However, the reason for the delay would be quite different, depending upon whether the display could be encoded as a unit (e.g., a word) or would need to be encoded on an element-byelement basis (e.g., a consonant array). First, however, in the case of a single-letter display, the complete display is the pattern that needs to be matched to the predesignated target, and therefore any unitary encoding would yield the encoding required by the task. That would mean that the needed comparison could be made quite quickly and without further processing.

If the display was a word, the processing would be more complicated. While the initial attempts to encode the display as a unit would succeed, just as for a single-letter display, the result would be a word-level encoding. The task, however, requires the subject to compare an encoding of the predesignated target with an encoding of a component letter, and that would require the perceiver to decode the word code into component letter codes, which would delay the detection decision and response. In addition, it should be noted that the reason subjects could not just go back to the display and encode the needed letter is that if they did so they again would see the wordlevel pattern, and, according to the model, that would just lead to another word-level code (i.e., pattern-level encoding is not optional).

For the case in which the display was a consonant array, the delay would occur because of the initial attempts (albeit unsuccessful) to encode the array as a unit. Only by the failure of those attempts would the perceiver have the information needed to know that the display could not be unitized, and that it would be necessary to parse the 
display and encode it on a letter-by-letter basis. However, while the required letter information then could be encoded directly, as opposed to being obtained indirectly or derivationally as in the case of a word, there would be a delay in the availability of those letter codes as a result of the initial unsuccessful attempts to encode the whole pattern as a unit.

This general model makes a number of predictions regarding how pattern-level and component-level information is handled that depend upon whether or not the display can be represented in an integrated manner with a unitary code. Most of these expectations center on the assumptions that, (1) for words, the word-level code should be available before codes for component letters are available, and (2) that letter-level processing should be done within memory rather than result from any direct encoding of letter information.

For nonintegratable arrays like consonants, on the other hand, it is assumed that (1) the pattern would be encoded into memory as a collection of component-level letter codes, with no unitary representation for the pattern, and consequently that (2) codes for component letters would be more immediately available for cognitive processing than any representation of the pattern as a whole (i.e., the opposite of what would be the case for words). The details of these expectations for words and consonant arrays, and their documentation, are available in several recent reports (Johnson, 1981, 1986a; Johnson, TurnerLyga, \& Pettegrew, 1986).

The term holistic processing has been used to characterize the events that led to these effects, and at a very straightforward level, that term can be defined operationally as cases in which the pattern-level representation is more immediately available for cognitive processing than are component-level representations. The foregoing considerations suggest that words are processed holistically, whereas for consonant arrays, although it may be attempted initially, holistic processing is unsuccessful, and some type of component-level processing is then required.

With respect to the present issue, if the target to be detected was a B and the display was B or L, the initial holistic encoding of the display would be successful, and the resulting code could be compared immediately to that for the predesignated target. If, however, the display were BQTMX or LQTMX, the perceivers would first attempt to cope with the entire pattern holistically, and although that would be unsuccessful, those initial attempts would delay the response in comparison to when the display was a single letter. Similarly, redundant displays such as BBBBB or LLLLL also would entail a delay in that neither of those displays, as complete patterns, matches anything for which the perceiver is likely to have a unitary encoding; and again the initial unsuccessful attempts at holistic encoding would delay the decision and response (i.e., BBBBB is essentially a rectangular pattern with a lot of small scribbles within it, whereas the display $B$ conforms to the pattern of the letter B).

Although there are demonstrations of the advantage in speed of letter deisction with single-letter displays over that with redundant multiletter displays (Eriksen \& Schultz, 1979; Johnson, 1977, 1981, 1986b), Krueger and Shapiro (1980) have reported a series of very similar experiments in which this single-letter advantage was not obtained. A recent pair of experiments (Johnson, 1986b) suggests that the basic phenomenon (i.e., the single-letter advantage) seems to be reliable and quite real, and that the differential outcome is probably attributable to some small methodological difference between the experiments. However, the problem is that the model from which this work began (Johnson, 1977) would predict that there always should be an advantage for single-letter displays, and the following series of experiments was designed to determine why Krueger and Shapiro (1980) failed to obtain the single-letter advantage.

\section{EXPERIMENTS 1 AND 2}

There were many seemingly trivial differences between the original set of experiments (see Johnson, 1977, 1981, for a brief description) and the experiments later reported by Krueger and Shapiro (1980). But even as the latter experiments were unfolding-and that included a situation in which an experimenter who had tested the subjects in one of the original experiments also tested the subjects in one of the Krueger and Shapiro experiments-the specific critical difference was not clear.

Although the most obvious difference was the fact that the original experiments used a tachistoscope, whereas Krueger and Shapiro (1980) used a computer-driven CRT display (green phosphor), there were other differences as well. For example, in contrast to the original experiments, in the Krueger and Shapiro experiments: (1) the redundant and nonredundant multiletter displays were separated into blocks of trials rather than being intermixed within the same block; (2) the predesignated targets were presented visually rather than orally; (3) the letters were separated by a single space to avoid crowding, rather than being adjacent; (4) the displays contained four letters rather than five; and (5) although subjects were to confine their search to only the initial letter position of the display, as in the earlier experiments, the predisplay fixation field was a plus sign immediately under that letter position rather than a large field of Xs. (There were other types of predisplay fixation fields in some of Krueger and Shapiro's experiments, and these will be considered later.)

The first two experiments in the present series were an attempt to approximate as closely as possible the conditions of the Krueger and Shapiro (1980) experiments, within the context of limitations imposed by some equipment differences. The displays appeared in the center of the screen of a video terminal (white phosphor on a dark background), and the predisplay fixation field consisted of an array of five dots or periods. The dots disappeared when the display appeared; the single-letter displays appeared in the location of the first dot, while the letters from the five-letter displays replaced each of the five dots. The subjects' task always was to determine whether the item in the location of the first dot matched the predesig- 
nated target, and the three types of display (i.e., single letters as well as redundant and nonredundant five-letter displays) were each presented in separate blocks of trials. The subjects were thoroughly informed regarding both the nature of the displays and the location in which to search for the target.

These conditions resulted in a set of procedures that seemed to approximate those used by Krueger and Shapiro (1980) in all critical ways. The only difference between Experiments 1 and 2 is that in the first experiment the predesignated target letter for each display was shown to the subjects (the procedure used by Krueger \& Shapiro), whereas in the second experiment the experimenter stated the predesignated target (the procedure used in Johnson, 1986b).

\section{Method}

Subjects. The sample sizes for the two experiments were 30 and 48 , respectively, and the subjects were students who participated as part of a course option.

Apparatus and Stimuli. The equipment consisted of a Northstar Horizon computer and two Televideo $920 \mathrm{C}$ terminals. The experimenter used one of the terminals to control the flow of the experiment, and the subjects used the other terminal. The displays were white characters on a dark background, with each character occupying a visual angle of approximately $.3^{\circ}$ centered on the subjects' video screen. The subjects responded by pressing the " $\mathrm{Z}$ " key for NO and the "?-l" key for YES.

The displays were typed in uppercase characters and presented in blocks of 80 displays each. A block of displays was homogeneous with respect to display type (i.e., single letter vs. five-letter redundant vs. five-letter nonredundant), and each subject was presented with two blocks of each type. The two blocks of each type were presented adjacently, and the six possible orders in which the three types of display could be presented were given to an equal number of subjects.

The 20 letters used were all the consonants except for $\mathrm{Y}$, and within a block there were four displays that used each consonant as the critical letter. For the single-letter displays, only that one letter was in the display, for the five-letter redundant displays, each display consisted of five instances of that letter; for the five-letter nonredundant displays, the initial letter was the critical one. For the nonredundant displays, the other four letters were all different from one another and different from the initial letter; across displays, each of the 20 consonants appeared equally often in these noncritical letter positions.

Within a block of displays, the predesignated target letter matched the critical letter for half the displays (i.e., YES items) and did not match it for the other displays (i.e., NO items). Each consonant appeared as the critical letter in two YES items and two NO items within each block, and which was YES and which was NO was counterbalanced across subjects. In the case of a NO item for the nonredundant displays, the predesignated target did not appear as one of the noninitial letters. Finally, a separate random order of presentation was used for each list for each subject.

Procedure. Immediately before a block of displays was presented, the nature of the displays and the task were described to the subject. The predisplay fixation field consisted of a row of five dots (periods), which disappeared approximately $300 \mathrm{msec}$ before the onset of the display. For the five-letter displays, each letter replaced one of the five dots; for the single-letter displays, the displayed consonant appeared in the location that had been occupied by the initial dot. The subjects were fully informed with regard to the location in which the displayed letters would appear relative to the dots, and they were told that the critical letter would appear in the location of the first dot.

For each display in Experiment 1, the predesignated target appeared on the subject's screen immediately before the onset of the predisplay fixation field, but in Experiment 2, the predesignated target was presented orally. In both experiments, a different predesignated target was used for each display. The experimenter then said "ready" and triggered the display sequence. The display sequence consisted of a clearing of the screen, followed by the predisplay fixation field, which remained on for approximately $500 \mathrm{msec}$. After a short interval (about $350 \mathrm{msec}$ ) this was followed by the display itself, which remained on until after the subject responded. The subject was then informed as to whether the response was right or wrong. The time between displays within a block was approximately $6 \mathrm{sec}$, and the time between the two blocks within a task was $10 \mathrm{sec}$.

For the five-letter displays, the subjects were instructed to determine whether the predesignated target matched the letter in the initial position of the display and they were told that, for the nonredundant displays, it would never appear in any other position (and it did not). In that the single-letter displays always appeared in the location of the initial dot of the predisplay fixation field, the subjects knew that for all conditions in the experiment the only display location that needed to be searched was that conforming to the letter that replaced the initial dot.

\section{Results}

The error data for the two experiments are presented in Table 1 . The only significant effect was for response type in Experiment $2[F(1,47)=7.45, p<.05]$; the effect of response type was the only factor to yield an $F$ greater than 1.00 in Experiment $1[F(1,29)=2.51$, $p>.05]$.

The latency data for the two experiments are presented in Table 2. An overall analysis of Experiment 1 indicated a reliable effect of display type $[F(2,58)=5.77, p<.05]$ and response type $[F(1,29)=98.83, p<.001]$, but the interaction was not reliable $[F(2,58)=1.30, p>.05]$. The same pattern of data was obtained for Experiment 2, with reliable effects for display type $[F(2,94)=5.77$, $p<.05]$ and response type $[F(1,47)=14.27, p<.01]$, but no interaction $(F<1.00)$.

Separate analyses indicated that the differences between the redundant and the single-letter displays were not reliable, with $F<1.00$ for both experiments, but there did appear to be a reaction-time advantage for the redundant displays over the nonredundant displays. That effect was

Table 1

Error Frequencies for Experiments 1 and 2

\begin{tabular}{lrrr}
\hline \multirow{2}{*}{$\begin{array}{c}\text { Response } \\
\text { Type }\end{array}$} & \multicolumn{3}{c}{ Display Type } \\
\cline { 2 - 4 } & Single & Redundant & Nonredundant \\
\hline YES & \multicolumn{3}{c}{ Experiment 1} \\
NO & 1.00 & 1.78 & 1.97 \\
Mean & 1.93 & 1.68 & 1.58 \\
& & 1.73 & 1.76 \\
YES & 1.42 & 1.76 & \\
NO & 1.31 & 1.26 & 1.54 \\
Mean & 1.36 & 1.51 & 1.27 \\
\hline
\end{tabular}


Table 2

Latency Data for Experiments 1 and 2

\begin{tabular}{lccc}
\hline \multirow{2}{*}{$\begin{array}{c}\text { Response } \\
\text { Type }\end{array}$} & Single & Redundant & Nonredundant \\
\hline & & Experiment 1 & \\
YES & 496 & 497 & 532 \\
NO & 576 & 564 & 596 \\
Mean & 536 & 530 & 564 \\
& & Experiment 2 & \\
YES & 495 & 492 & 523 \\
NO & 475 & 477 & 499 \\
Mean & 485 & 484 & 511 \\
\hline
\end{tabular}

reliable for Experiment $2[F(1,47)=16.92, p<.01]$ but fell short of reliability for the first experiment $[F(1,29)$ $=2.48, p>.05]$.

\section{Discussion}

With regard to the goal of trying to reproduce the Krueger and Shapiro (1980) effects, the almost complete absence of any difference between the single-letter displays and the redundant displays (i.e., the single-letter advantage) in either experiment suggests that the experiments were quite successful. The suggestion that all that can be seen in these data is a lack of reliability stemming from not having enough observations can be countered by noting that this number of observations yielded highly reliable differences between comparable conditions in the earlier experiments (Johnson, 1986b). In addition, that explanation cannot account for the fact that the small difference that did occur in each experiment was in the wrong direction.

One outcome that did not match the Krueger and Shapiro (1980) results was the failure in the first experiment to obtain a significant difference between the redundant and the nonredundant displays. The effect was rather large in absolute terms ( $34 \mathrm{msec}$ ), and in the expected direction, and it is possible that, in this case, a lack of reliability in the data is the explanation. Again, however, it should be noted that the effects obtained in the prior studies, which used a comparable number of observations, were highly reliable, as was the 27 -msec difference obtained in Experiment 2.

\section{EXPERIMENT 3}

Krueger (personal communication, 1987) suggested one potentially critical difference between the Krueger and Shapiro (1980) and the original Johnson (1977) experiments: Krueger and Shapiro presented the redundant and the nonredundant five-letter displays in separate blocks of trials, whereas Johnson presented them randomly within the same block, such that subjects could not adopt consistent strategies. Although the results reported by Johnson (1986b) indicate that the single-letter advantage still can be obtained if display type is blocked when the procedures are otherwise similar to those used in the origi- nal experiments, in fact there did appear to be a marked reduction in both the magnitude of the effect and its reliability. Therefore, in Experiment 3 the redundant and nonredundant displays were intermixed within blocks of display trials.

\section{Method}

This experiment was identical to the second experiment, with the single exception that the two types of five-letter display (i.e., redundant and nonredundant) were randomly intermixed within blocks. Half the subjects received the two blocks of single-letter displays before the four blocks of five-letter displays; the other half received them in the reverse order. The subjects were 16 students from the same population that was used for the prior experiments.

\section{Results}

The error data are presented in Table 3 . Neither the effect of display type $[F(2,15)=2.18, p>.05]$ nor the effect of response type $[F(1,15)=1.59, p>.05]$ was significant, but there was a reliable interaction $[F(2,30)$ $=5.87, p<.05]$. The correlation between errors and latency was -.03 , but when response type was eliminated as a factor (by averaging across response type), it increased to +.97 . On the whole, there is little evidence of any problem with a speed-accuracy tradeoff.

The latency data are presented in Table 4 . In the overall analysis, the effect of response type was significant $[F(1,15)=66.25]$, as was the effect of display type $[F(2,30)=4.01, p<.05]$, but the interaction was not significant $(F<1.00)$. The separate analyses indicated no difference between the single-letter displays and the redundant displays $(F<1.00)$, but again there was a reliable advantage of redundancy for the five-letter displays $[F(1,15)=19.92, p<.01]$.

\section{Discussion}

Although the sample size was very small, the data are reliable and quite clear. Again, the Krueger and Shapiro (1980) result was obtained (i.e., no single-letter advantage), although, at the same time, when the displays contained five letters there was an unambiguous advantage for redundancy. Clearly, the possibility (or lack thereof)

Table 3

Error Frequencies for Experiment 3

\begin{tabular}{lccc} 
Response & \multicolumn{3}{c}{ Display Type } \\
\cline { 2 - 4 } Type & Single & Redundant & Nonredundant \\
\hline YES & 2.93 & 3.60 & 6.07 \\
NO & 4.13 & 3.87 & 3.07 \\
Mean & 3.53 & 3.73 & 4.57 \\
\hline
\end{tabular}

Table 4

Latency Data for Experiment 3

\begin{tabular}{cccc}
\hline & \multicolumn{3}{c}{ Latency Data for Experiment 3 } \\
\cline { 2 - 4 } Response & Single & Redundant & Nonredundant \\
Type & 489 & 494 & 521 \\
YES & 489 & 561 & 583 \\
NO & 568 & 527 & 552 \\
Mean & 529 & & \\
\hline
\end{tabular}


of adopting differential strategies for the two types of display does not seem to be the critical issue.

While, to a degree at least, these conclusions require us to accept the null hypothesis, the consistency of obtaining no difference between the single-letter displays and the redundant displays is impressive. The largest difference was in the first experiment, and that was only $6 \mathrm{msec}$ (in the wrong direction); in the other two experiments, the differences were 1 and $2 \mathrm{msec}$ (again in the wrong direction). When that stability is combined with the fact that the data obtained in this experiment (with only 16 subjects) were sufficiently reliable to readily detect a rather small difference (e.g., $25 \mathrm{msec}$ ) attributable to redundancy, it does seem reasonable to conclude that, within the context of these procedures, the absence of a single-letter advantage appears to be quite real.

\section{EXPERIMENT 4}

The two remaining differences between the original experiments and those reported by Krueger and Shapiro (1980) that might reasonably explain the differential results are mode of display presentation-CRT versus tachistoscope-and the nature of the predisplay fixation field. Of these options, not only does display mode seem to be the less likely candidate, but several investigators (e.g. , Grice, Canham, \& Boroughs, 1983; Keren \& Boer, 1985) have demonstrated that in both reaction time tasks and tachistoscopic tasks like that used by Bjork and Murray (1977) holistic processing, or global precedence (Navon, 1977), seems to occur only when there is some positional uncertainty regarding the location of the critical targets (but see La Heij \& van der Heijden, 1983, for a demonstration of the effect when there is no positional uncertainty).

With regard to predisplay fixation field, the original experiments (Johnson, 1977, 1981) used a large predisplay fixation field that consisted of many rows of Xs with a dot in the center, whereas Krueger and Shapiro (1980) used either a plus sign immediately under the location in which the critical letter would appear or a large field of characters that contained a rectangle in the location in which the display would appear. Both the plus sign and the left vertical of the rectangle provided a clear mark for the location of the upcoming critical letter, but the large field of Xs used in the original experiments (Johnson, 1986a) did not provide any unique character in the critical position that would make it stand out (the dot corresponded to the center of the display).

In the present series of studies the first three experiments were similar to Krueger and Shapiro's (1980) in that the leftmost dot in the prefixation field was the critical position, and that position could be identified quite readily. In Experiment 4, the fixation field was an array of Xs that was larger than the dimensions of the subsequent display and no unique character appeared in the position that would be occupied by the critical letter in the upcoming display. However, the subjects were thoroughly informed regarding which $\mathrm{X}$ in the predisplay fixation field corresponded to the position of the critical letter in the upcoming display (the fourth $\mathrm{X}$ in the middle of three rows); the only difference between this experiment and the third experiment was that there was nothing that made that position stand out. In that sense, then, the change from the third experiment was not so much in the degree of positional certainty regarding where the critical letter would appear, but more a change in terms of whether the subjects had a cue that stood out from its background that could be used as a focal point for establishing a narrow focus of attention on the critical location prior to the onset of the display.

\section{Method}

The procedures for this experiment were exactly the same as for Experiment 3, with the single exception that the predisplay fixation field consisted of three consecutive rows of $11 \mathrm{Xs}$ instead of five dots. The fixation field disappeared approximately $350 \mathrm{msec}$ before the onset of the display. The first letter of the five-letter displays, as well as the single letter in the single-letter displays, appeared in the location of the fourth $\mathrm{X}$ of the middle row, and the subjects were informed of that fact.

The subjects were 32 students from the same population as that used for the previous experiments.

\section{Results}

The error data are given in Table 5. Neither the effect of display type $(F<1.00)$ nor response type $[F(1,31)$ $=1.56, p>.05]$ were reliable, but there was a significant interaction $[F(2,62)=4.97, p<.05]$. The overall correlation between errors and latency was -.40 , which jumped to -.99 when response type was eliminated as a factor by averaging across response type. However, for the scores involved in the comparison between the singleletter displays and the redundant displays the correlation was +.05 , and since there were no significant differences in the error rates among the various display types, there does not seem to be any serious problem with speedaccuracy tradeoffs.

The latency data are presented in Table 6 . The overall analysis indicated reliable effects of display type $[F(2,62)$ $=23.99, p<.01]$ and response type $[F(1,31)=127.82$, $p<.001]$, but the interaction was not significant $[F(2,62)$ $=2.58, p>.05]$. Separate analyses indicated that this time there was a significant advantage for the single-letter displays over the redundant displays $[F(1,31)=11.95$, $p<.01]$, as well as the usual redundancy advantage for the multiletter displays $[F(1,31)=35.76, p<.01]$.

Table 5

Error Frequencies for Experiment 4

\begin{tabular}{lccc}
\hline \multirow{2}{*}{$\begin{array}{c}\text { Response } \\
\text { Type }\end{array}$} & \multicolumn{3}{c}{ Display Type } \\
\cline { 3 - 4 } & Single & Redundant & Nonredundant \\
\hline YES & 3.56 & 2.72 & 3.69 \\
NO & 2.94 & 3.50 & 2.25 \\
Mean & 3.25 & 3.11 & 2.97 \\
\hline
\end{tabular}


Table 6

Latency Data for Experiment 4

\begin{tabular}{lccc}
\hline \multirow{2}{*}{$\begin{array}{c}\text { Response } \\
\text { Type }\end{array}$} & Single & Redundant & Nonredundant \\
\hline YES & 535 & 563 & 596 \\
NO & 610 & 640 & 657 \\
Mean & 572 & 601 & 627 \\
\hline
\end{tabular}

\section{Discussion}

These results suggest that the difference in outcome between Johnson's $(1977,1981,1986 \mathrm{~b})$ experiments and those reported by Krueger and Shapiro (1980) may be due to the nature of the predisplay fixation field. When the items within the field are relatively discrete (i.e., dots), and are limited to the number of items that will appear within the subsequent display, it may be somewhat easier for the subjects to prefocus their attention on the specific location of the critical item within the upcoming display than would be the case if the predisplay fixation field was somewhat more amorphous (e.g., an array of Xs).

\section{EXPERIMENT 5}

The fifth experiment simply replicated the conditions of the third and fourth experiments, but did so within the context of a single experiment such that the differential outcomes could be compared directly.

\section{Method}

The experiment involved a mixed design in which the type of predisplay fixation field was the between-subjects factor. The methods and procedures for the dot-field condition and the X-field condition were exactly as those employed in the third and fourth experiments, respectively, and the subjects were assigned to conditions in alternating order as they appeared for the experiment.

The subjects were 40 students ( 20 per condition) from the same population as that used in the prior experiments.

\section{Results}

The error data are presented in Table 7. An overall analysis indicated a reliable effect of response type $[F(1,38)=10.89, p<.01]$ as well as a display type $\times$ response type interaction $[F(2,76)=8.11, p<.01]$ and a conditions $\times$ display type $\times$ response type interaction $[F(2,76)=4.04, p<.05]$. None of the other main effects or interactions were reliable $(F<1.00$ in each case).

The reaction time data are presented in Table 8 . The overall analysis indicated significant effects of display type $[F(2,76)=10.93, p<.01]$ and response type $[F(1,38)$ $=103.24, p<.001]$, but the effect of conditions was not significant $(F<1.00)$. In addition the conditions $\times$ display type interaction was significant $[F(1,38)=4.48$, $p<.05]$, but the conditions $\times$ response type interaction $(F<1.00)$, the display type $\times$ response type interaction $[F(2,76)=2.36, p>.05]$, and the three-way interactior $(F<1.00$ ) were not reliable.

Separate analyses indicated that the single-letter displays had a shorter latency than the redundant displays $[F(1,38)$
$=4.88, p<.05]$, but the effect interacted with conditions $[F(1,38)=5.29, p<.05]$. That interaction reflects the fact that although again there was no difference at all between the two display types for the dot-field condition, there was a clear single-letter advantage for the $\mathrm{X}$-field condition $[F(1,19)=7.58, p<.05]$.

The redundancy effect also was significant $[F(1,38)=$ $26.02, p<.01$ ], but while it did interact with response type $[F(1,38)=5.43, p<.05]$, it did not interact with conditions $(F<1.00)$. That is, redundancy had a somewhat larger effect on the YES responses than on the NO responses, but the nature of the predisplay fixation field seemed not to influence the pattern of the data.

\section{Discussion}

These data, combined with those from the fourth experiment, seem to offer clear support for the notion that the nature of the predisplay fixation field determines whether these experiments yield data similar to those reported by Krueger and Shapiro (1980) or similar to those reported by Johnson $(1977,1981,1986 \mathrm{~b})$. When the field consisted of an array of Xs, there was a significant singleletter advantage that was reliably greater than that obtained when the field consisted of five dots; in the latter case, there was no evidence of any single-letter advantage at all.

These data also are of interest with regard to the role played by redundancy in tasks such as these. Specifically, the data indicate that providing the subjects with an anchor point on which they can narrowly prefocus their attention is a sufficient condition for eliminating the disad-

Table 7

Error Frequencies for Experiment 5

\begin{tabular}{lccc}
\hline $\begin{array}{c}\text { Response } \\
\text { Type }\end{array}$ & Single & Redundant & Nonredundant \\
\hline & & Dot-Field & \\
YES & 2.40 & 1.95 & 3.40 \\
NO & 1.75 & 2.20 & 1.50 \\
Mean & 2.08 & 2.08 & 2.45 \\
& & X-Field & \\
YES & 2.60 & 2.15 & 2.40 \\
NO & 1.15 & 2.30 & 1.85 \\
Mean & 1.88 & 2.23 & 2.13 \\
\hline
\end{tabular}

Table 8

Latency Data for Experiment 5

\begin{tabular}{lccc}
\hline $\begin{array}{c}\text { Response } \\
\text { Type }\end{array}$ & Single & Redundant & Nonredundant \\
\cline { 3 - 4 } & & Dot-Field \\
YES & 588 & 578 & 625 \\
NO & 671 & 678 & 695 \\
Mean & 630 & 628 & 660 \\
& & X-Field & \\
YES & 570 & 634 & 674 \\
NO & 644 & 729 & 745 \\
Mean & 607 & 682 & 709 \\
\hline
\end{tabular}


vantage of multiletter arrays (i.e., the single-letter advantage). However, allowing for the possibility of such prefocusing of attention seems to have no influence on the redundancy effect. That would suggest that the redundancy effect was independent of the manner in which the perceivers deployed their attention.

One tempting interpretation of these results is to suggest that the letter information from all of the positions is encoded automatically, with no attentional resources required (LaBerge, 1973), and that the interference from the nonredundant noninitial letters stems from the fact that they signal a response inconsistent with that signaled by the initial letter. However, there are two problems with that interpretation. First, it would explain the redundancy effect only for the YES responses, because the response signaled by the noninitial letters in the case of a NO item would be the same as that signaled by the initial letter. Although there was a reduced effect for the NO items in this experiment, in fact there was a reliable difference, and in the prior study (Johnson, 1986b) the redundancy effect was actually larger for the NO items than for the YES items.

The second problem stems from the fact that if, for a NO item, the predesignated target did not appear in the initial position, but did appear elsewhere in the array, it would signal an incompatible YES response. The interference that would result from that item then should slow down the subjects' responses relative to a condition in which the predesignated target did not appear in the array (i.e., all the letters signal the same NO response). For example, if subjects were to determine whether a display began with the letter $B$, their NO response should be slower if the display was QTLFB than it if was QTLFJ.

Unfortunately, that does not seem to be the case (Johnson, 1986a). When the displays consisted of consonant arrays and subjects were to determine whether the predesignated target matched the initial letter of the display, the presence or absence of the target in noninitial positions was irrelevant, as was its serial position when it did appear (i.e., given B as the predesignated target, displays such as QTLFJ, QBLFJ, and QTLFB all yielded the same fast NO response).

An alternative interpretation of the advantage of redundant over nonredundant multiletter displays (i.e., the redundancy effect) is that it may stem from the fact that subjects might be able to detect the redundancy before the letters are specifically encoded, and that they do so on the basis of the physical regularity of the pattern when it is redundant (Johnson, 1986b). Similarly, with only a single-letter display, the perceiver would know it was a single letter simply on the basis of the physical size of the display.

If, however, the display was redundant, or consisted of only a single letter, having that information before their decision would allow the subjects to make a decision on the basis of the very first letter encoded regarding whether or not there was a match with the predesignated target. On the other hand, if the display contained more than one letter, but was not redundant, at the very minimum it would be necessary to check the positional information for an encoded letter before responding. In addition, if the item in the initial letter position was not the first one encoded (see Mason, 1982, for a recent treatment of this issue), it would be necessary for a subject to delay a decision until that item had been encoded. Clearly, if the size or physical regularity of the displayed array signaled the subject that the first item encoded, regardless of its serial position, would be a valid data source for making a response decision before the encoding process began, then responses should be faster than if subjects also needed to use positional information in some way.

\section{GENERAL DISCUSSION}

Although these data do seem clear in pointing to the basis for the difference between the data reported by Johnson (1986b) and those reported by Krueger and Shapiro (1980), they do raise problems for the pattern-unit model. That is, the data suggest the importance of an attentional mechanism as an explanation for the fact that pattern-level information seems to be more immediately available than is component-level information. However, although that explanation for the effect fits in very nicely with some models (e.g., that proposed by Johnston \& McClelland, 1980), the pattern-unit model attributes the effect to the nature of the encoding process-and that does not seem to be completely consistent with the operation of an attentional mechanism.

Specifically, the Johnston and McClelland (1980) model assumes bottom-up processing, in which the initial encoding is of letter features, with those encodings then being used to activate letter codes, which in turn activate word codes. In addition, Johnston and McClelland's model assumes that not only do component encodings at one level activate representations with which they are consistent at the next level, but those encodings also are assumed to actively inhibit next-level encodings with which they are inconsistent.

Most critically, the model assumes further that if perceivers needed to use any of the information from within the display in order to determine a response, it would be necessary for them to deploy their attention to the appropriate encodings, but that they would do so only after the encoding process was complete. However, the model assumes that such deployment of attention would occur in a top-down manner, with attention first going to the pattern-level encoding, and only then down through intermediate-level encodings to the encodings of the very basic-level components such as features.

In this way, the Johnston and McClelland (1980) model also would predict the pattern of data described earlier as defining holistic processing (i.e., with pattern-level information being more immediately available for cognitive manipulation than component-level information). However, rather than suggesting that it reflects the order of cognitive encoding, as does the pattern-unit model, 
Johnston and McClelland's position suggests that it reflects the order in which subjects attend to the encodings once the encoding process is complete.

In terms of the present data, it appears that a singleletter advantage is not obtained when subjects have a means whereby they can preset their attention to a narrowly defined spatial position. On the other hand, evidence of early attempts at holistic processing (i.e., a single-letter advantage) is obtained when subjects do not have such a discrete anchor point on which to narrowly prefocus their attention. Outcomes of that sort would seem to suggest that what has been defined as holistic processing may depend critically upon the manner in which subjects deploy and focus their attention. In fact, as assumed by Johnston and McClelland (1980), it may be the manner in which attention is deployed and focused.

LaBerge (1983) also has offered evidence that subjects can prefocus their attention in tasks such as these (see Eriksen \& Yeh, 1985; Eriksen \& St. James, 1986; Jonides, 1980, 1983; LaBerge \& Brown, 1986; Podgorny \& Shepard, 1983; and Posner, 1980; for additional treatments of these issues). In separate blocks of trials, LaBerge's subjects were to determine either whether a five-letter array was a familiar name or the middle letter conformed to a predesignated target. The predisplay fixation field consisted of five \# symbols, with one occupying each of the five letter positions. However, on some trials in both of those blocks, instead of being five letters, the display was a single critical item with + symbols occupying the other four positions. On those trials, the subject was to respond YES if the critical item was a 7 and not respond at all if it was not a 7, and the critical item could appear in any one of the five positions.

LaBerge's (1983) data indicated that if the subjects' major task within a block of trials was to respond to the middle letter of the words, on those occasions when the 7 and + symbols appeared instead of the expected word, the subjects responded faster when the 7 appeared in the middle position and slower when it appeared farther from the middle position in either direction. However, if their major task was to focus on word-level decisions for that block of trials (i.e., is the display a familiar name?), that $\mathrm{V}$-shaped serial position effect for reaction time was not obtained, and the function was, in fact, quite flat. These results would seem to suggest that not only can subjects use the predisplay fixation field as a basis for presetting their focus of attention, but how broadly or narrowly they preset their focus can be determined by the nature of the task they must perform with the upcoming display.

Within the context of these considerations, one way to account for the dat $a$ from the present experiments is to assume that subjects normally maintain a broad, but undefined, focus of attention such that whenever they encounter a visual pattern, the pattern itself defines the focus of attention. If their task was to deal with a component of a pattern, that assumntion would imply that they could do so only after they had already attentionally processed the pattern as a unit, but they then would be further delayed because they would have to shift their focus of attention to a specific component position. At that point they could use their attention to process the component item, but their response time would be longer than it would have been had they been able to base a decision on the first encoding to which their attention had been deployed (i.e., a representation of the entire pattern).

However, if the predisplay fixation field contained a unique and readily identifiable element of some sort in the specific spatial location that would be occupied by the critical letter in the following target display, it is quite possible that subjects could quickly locate that cue and then use it as a basis for narrowly focusing their attention on that position in space. If the predisplay fixation field was then replaced immediately by the display, the perceiver's attention already would be locked onto the cognitive representation of "the place in the world" in which they would find the information with which they would need to cope, and there would be no preliminary automatic encoding of irrelevant pattern-level information. In addition, there would be no subsequent need for them to change either their level of attentional focus or the locus of their attention. Given that situation, whether the item within that display position was the only item in the display or a component of a larger pattern would be irrelevant, because the perceiver's attentional focus would exclude everything but the contents of the critical location.

In general, then, these data seem most consistent with a model of pattern perception that assumes that the order in which subjects are able to respond to the various levels at which a pattern can be represented (e.g., pattern-level vs. component-level) is determined by the order in which attention can be deployed to those levels of representation and not by the order in which they were originally established. Furthermore, it is assumed that such deployment normally occurs first to the pattern-level representation, and only then to component-level representation. In addition, that particular order of deployment is assumed to be determined by the fact that attention usually has a broad nonspecific focus, and whenever a pattern is encountered, it is the pattern as a whole that determines the subsequent focus (i.e., given a nonspecific prefocus, we always set our subsequent focus of attention to include the whole of any encountered pattern).

However, this set of assumptions indicates that the pattern as a whole should be the determiner of the subsequent focus of attention only if the attentional shift to the pattern begins from a nonspecific focus. This view would assume that if the subject was prefocused on a specific spatial location (i.e., a specific spatial extent) prior to the onset of a display, it would be the items from the display represented within that spatial extent that would receive the initial attentional processing rather than the patternlevel representation.

Although this account can handle the data from the present experiments quite well, the results of studies such as Grice et al.'s (1983) and Keren and Boer's (1985) re- 
quire an additional assumption. In those experiments, the subjects were allowed to narrowly prefocus their attention prior to the onset of the display, such that the breadth of focus included only the component-level representations they needed to handle the task. If the target display then appeared with the critical component being in the same spatial location as was the point the subjects had used to preset their focus of attention, there was no evidence of holistic processing or global precedence. That is, there was no interference in the detection of a component from either the overall pattern or other components.

However, if the subjects needed to shift their attention to a different spatial location when the display appeared, even though the spatial extent of the needed focus remained unchanged, they seemed to lose the narrow prefocus. That is, under those circumstances, when subjects needed to detect a component they did seem to encounter interference from both other components and the pattern as a whole. Similarly, in La Heij and van der Heijden's (1983) Experiment 3, although the subjects knew where the target would appear, and they were able to appropriately prefocus their attention, there was an interference effect from adjacent letters. Again, however, a shift of attention was required since the location of the predisplay focus point and that of the subsequent target were not the same, although in this case the needed shift was only $.1^{\circ}$ of visual angle.

In general, these results suggest that when attention is shifted from one spatial location to another, the spatial extent of the focus also may change in extent from what it was before the shift to being nonspecific after the shift. In addition, it would be assumed that the extent of any subsequent focus would be completely determined by the scope of the whole of the first pattern encountered after the shift. This account is, of course, ad hoc and does not have strong independent support, although the LaBerge (1983) data do indicate a decrement in performance when a relatively small shift in locus of attention is required.

Overall, then, this view, like the Johnston and McClelland (1980) position, attributes what has been defined as holistic processing to the order in which attention is deployed to the various levels of representation at which information has been encoded, and not to the encoding process itself. In addition, within that view, unless attention has been narrowly prefocused, it is assumed that it is the pattern as a whole that determines the initial level of attentional focus.

\section{REFERENCES}

Bjork, E. L., \& MURRAY, J. T. (1977). On the nature of input channels in visual processing. Psychological Review, 84, 472-484.
Eriksen, C. W., \& Schultz, D. W. (1979). Information processing in visual search: A continuous flow conception and experimental results. Perception \& Psychophysics, 25, 249-263.

ERIKSEN, C. W., \& ST. JAMES, J. D. (1986). Visual attention within and around the field of focal attention: A zoom lens model. Perception \& Psychophysics, 40, 225-240.

ERIKSEN, C. W., \& YEH, Y.-Y. (1985). Allocation of attention in the visual field. Journal of Experimental Psychology: Human Perception \& Performance, 11, 583-597.

Grice, G. R., Canham, L., \& Boroughs, J, M. (1983). Forest before the trees? It depends where you look. Perception \& Psychophysics, 33, $121-128$.

JoHNSON, N. F. (1977). A pattern unit model of word identification. In D. LaBerge \& S. J. Samuels (Eds.), Basic processes in reading: Perception and comprehension. Hillsdale, NJ: Erlbaum.

JoHNSON, N. F. (1981). Integration processes in word recognition. In O. J. Tzeng \& H. Singer (Eds.), Perception of print: Reading research in experimental psychology. Hillsdale, $\mathrm{NJ}$ : Erlbaum.

JoHnson, N. F. (1986a). On looking at letters within words: Do we "see" them in memory? Journal of Memory \& Language, 25, 558-570.

Johnson, N. F. (1986b). On the detection of letters within redundant arrays. Perception \& Psychophysics, 40, 93-100.

Johnson, N. F., Turner-Lyga, M., \& Pettegrew, B. S. (1986). Partwhole relationships in the processing of small visual patterns. Memory \& Cognition, 14, 5-16.

Johnston, J. C., \& MCClelland, J. L. (1980). Experimental test of a model of word identification. Journal of Verbal Learning \& Verbal Behavior, 19, 503-524.

JoNidEs, J. (1980). Towards a model of the mind's eye's movement. Canadian Journal of Psychology, 34, 103-112.

JoNiDES, J. (1983). Further toward a model of the mind's eye's movement. Bulletin of the Psychonomic Society, 21, 247-250.

KereN, G. , \& BoER, L. C. (1985). Necessary conditions for repeatedletter inferiority: The role of positional uncertainty. In M. I. Posner \& O. S. M. Marin (Eds.), Attention and performance XI (pp. 601612). Hillsdale, NJ: Erlbaum.

Krueger, L. E., \& SHAPIRo, R. G. (1980). Repeating the target neither speeds nor slows its detection: Evidence for independent channels in letter processing. Perception \& Psychophysics, 28, 68-76.

LABERGE, D. (1973). Attention and the measurement of perceptual learning. Memory \& Cognition, 1, 268-276.

LABERGE, D. (1983). Spatial extent of attention to letters and words. Journal of Experimental Psychology: Human Performance \& Perception, 9, 371-379.

LABERGE, D., \& BRown, V. (1986). Variations in the size of the visual field in which targets are presented: An attentional range effect. Perception \& Psychophysics, 40, 188-200.

La Heij, W., van der Heijden, A. H. C. (1983). Feature-specific interference in letter identification. Acta Psychologica, 53, 37-60.

Mason, M. (1982). Recognition time for letters and nonletters: Effects of array size, serial position, and processing order. Journal of Experimental Psychology: Human Performance \& Perception, 8 , 724-738.

NAvon, D. (1977). Forest before the trees: The precedence of global features in perception. Cognitive Psychology, 9, 353-383.

Podgorny, P., \& SHePARd, R. N. (1983). Distribution of visual attention over space. Journal of Experimental Psychology: Human Perception \& Performance, 9, 380-393.

PosNer, M. I. (1980). Orienting of attention. Quarterly Journal of Experimental Psychology, 32, 3-25.

(Manuscript received June 19, 1986; revision accepted for publication July 13, 1987.) 